\title{
(In)Segurança alimentar no contexto da pandemia por SARS-CoV-2
}

\author{
Food (in)security in the context of the SARS-CoV-2 \\ pandemic
}

\section{(In)Seguridad alimentaria en el contexto de la pandemia por SARS-CoV-2}

\author{
Tatiana Coura Oliveira 1 \\ Monise Viana Abranches 1 \\ Raquel Martins Lana 2,3
}

doi: 10.1590/0102-311X00055220
O avanço do novo coronavírus, denominado SARS-CoV-2, sobre os países tem gerado a interrupção das atividades cotidianas da população, devido à necessidade de isolamento social para frear o avanço da doença, que em menos de 4 meses já expandiu para 190 países, incluindo o Brasil 1. Os principais sinais e sintomas provocados pelo vírus incluem febre, tosse e dificuldade para respirar ${ }^{2}$. Sintomas gastrointestinais, como diarreia, vômitos e dor abdominal também foram relatados para a COVID-19, assim como nas infecções por outros coronavírus ${ }^{3}$. A transmissão da doença costuma ocorrer pelo ar ou pelo contato direto das pessoas e se dá por meio de gotículas de saliva, espirro, tosse e secreções que podem contaminar mãos e superfícies 2 .

Como tentativa de frear a propagação do vírus, a Organização Mundial da Saúde (OMS) e as principais autarquias de saúde no Brasil divulgaram como cuidados: higienizar as mãos, cobrir a boca com o antebraço ou lenço descartável ao tossir e espirrar, evitar aglomerações e manter-se em isolamento domiciliar, por até 14 dias, em caso de sintomas da doença 4 . Também é incentivada a manutenção das pessoas em ambientes bem ventilados 5 e que as empresas e instituições públicas considerem a realização de trabalho remoto (home office), reuniões virtuais e cancelamento de viagens.

No Brasil, os esforços neste estágio inicial da epidemia estão voltados para o enfrentamento do SARS-CoV-2, especialmente no sentido de evitar sua propagação 6 e, ao mesmo tempo, possibilitar o atendimento em saúde dos casos graves. Entretanto, outra face que se apresenta é a da segurança alimentar. Itália, Espanha e Portugal, já em quarentena, desenvolveram iniciativas para evitar aglomerações que impactaram a cadeia de alimentos. Nesses países, muitos estabelecimentos comerciais de refeições estão fechados e os supermercados passaram a implantar regras para acesso e aquisição de produtos, a fim de evitar o desabastecimento.

\section{Segurança: do controle higiênico-sanitário ao consumo de alimentos}

Apesar de estarmos vivenciando os efeitos preliminares da pandemia, a discussão sobre o quadro brasileiro de segurança alimentar e suas interfaces, tendo em vista o que já ocorreu nos países europeus, é de extrema urgência. Inúmeras incertezas perpassam o setor de alimentos, sendo escassas as orientações sobre o tema, seja em nível de produção, distribuição, comercialização ou preparo domiciliar.
1 Instituto de Ciências Biológicas e da Saúde, Universidade Federal de Viçosa, Rio Paranaíba, Brasil.

2 Núcleo de Métodos Analíticos para Vigilância em Saúde Pública, Rio de Janeiro, Brasil.

3 Programa de Computação Científica, Fundação Oswaldo Cruz, Rio de Janeiro, Brasil.

\section{Correspondência}

T. C. Oliveira

Instituto de Ciências Biológicas e da Saúde, Universidade Federal de Viçosa.

Rod. MG 230, Km 7, Rio Paranaíba, MG 38810-000, Brasil.

tatiana.coura@ufv.br 
O Ministério da Saúde assumiu o protagonismo na divulgação inicial dos cuidados junto à população, embasando-se especialmente nas diretrizes da OMS. Paralelamente, estados e municípios tentam amortecer os desdobramentos da doença emitindo decretos complementares à esfera federal, considerando suas particularidades no que tange a aspectos geográficos, econômicos, sociais, de saúde, dentre outros. Basicamente, a dispersão de aglomerações e o incentivo ao isolamento social, tendo em vista a elevada transmissibilidade do SARS-CoV-2 7, estruturam as ações das Unidades Federativas.

No nível institucional, os estabelecimentos que produzem refeições e que atendem às pessoas sadias, como trabalhadores nas empresas e estudantes (creches, escolas e universidades) tiveram seus serviços reduzidos ou paralisados. Em contrapartida, aqueles que atendem os hospitais e instituições de longa permanência para idosos são desafiados a produzir em maior escala, no primeiro caso, e com mais atenção quanto às questões higiênico-sanitárias pela vulnerabilidade do público, em ambos os casos. O Conselho Federal de Nutricionistas emitiu recomendações sobre as boas práticas para a atuação do nutricionista e do técnico em nutrição e dietética 8, como tentativa de preencher lacunas deixadas pela carência de capilaridade da Vigilância Sanitária no quesito alimentação coletiva em todo país.

Com o intuito de adotar ações que reduzem o risco de paralisação do serviço de abastecimento de alimentos, a Secretaria de Estado de Agricultura, Pecuária, Pesca e Abastecimento do Estado do Rio de Janeiro instituiu, por meio da Portaria PRESI/CEASA-RJ no 17, no dia 16 de março, o Programa Extraordinário de Prevenção à Contaminação. Essa ação estabelece a necessidade de adesão ao programa e notificação de todas as empresas que direta ou indiretamente prestam serviços às Centrais de Abastecimento, especialmente as entidades que produzem e fornecem gêneros alimentícios e as que comercializam, prestam serviços e utilizam a central. Dentre as medidas estabelecidas destacamos: evitar contato pessoal entre os colaboradores, dando preferência ao uso de tecnologias para a comunicação; realizar as refeições na própria estação de trabalho; restringir aos colaboradores a presença na sede e notificar os casos suspeitos 9 .

O Distrito Federal, no âmbito dos serviços de alimentação, instituiu no dia 14 de março o espaçamento de dois metros entre as mesas 10, já o Rio de Janeiro, por meio do Decreto no 46.973, de 16 de março, restringiu a capacidade de lotação dos estabelecimentos para $30 \%$, sendo mantida a normalidade dos serviços de entrega e de retirada das refeições no próprio local 11. Constata-se que na medida em que o número de casos de COVID-19 aumenta, novas estratégias são implantadas, mas a velocidade destas mudanças não é compatível com o avanço da doença. São Paulo, a exemplo disso, publicou, num intervalo de dez dias, seis decretos 12, além de reconhecer estado de calamidade pública, adotando medidas temporárias e emergenciais de prevenção de contágio pelo vírus.

As normativas publicadas até o dia 23 de março catalisaram o fechamento de muitos estabelecimentos de refeições coletivas e a migração de outros tantos para os serviços de take out/away e delivery. Essa adaptação dos serviços teve como foco principal a sobrevivência desse setor da economia no momento de crise. As empresas buscam manter os custos fixos, como salários de funcionários e aluguéis, bem como otimizar os custos variáveis. Essa adaptação, no entanto, pode ser insuficiente para conter a previsão de corte de 3 milhões de vagas de emprego no setor pelos próximos 40 dias, segundo a Associação Brasileira de Bares e Restaurantes 13. A mesma está sensível ao problema e tem intermediado negociações com o governo, com empresas do ramo de entrega de refeições, cujo pedido é feito pela Internet 14, além de publicar orientações aos empresários em relação aos cuidados de higiene no delivery ${ }^{15}$. Se por um lado a entrega em domicílio é uma solução viável para minimizar a crise do setor nos grandes centros urbanos, por outro, considerando as diferenças socioeconômicas e territoriais brasileiras, sabe-se que essa tecnologia não está acessível a toda população. É importante ressaltar que a precarização do trabalho, que vem se cristalizando nos últimos anos, e que inclui as atividades realizadas por meio das plataformas virtuais, aumenta a vulnerabilidade dos entregadores e os coloca na linha de frente de exposição ao SARS-CoV-2.

Quem não tem acesso à estratégia de delivery e, também, em função das medidas de isolamento social, prepara suas refeições em casa. Para tanto, essas pessoas precisam adquirir gêneros alimentícios, itens de cuidados pessoais e de limpeza, mas a ida ao supermercado torna-se um fator de risco quando este não está preparado para atender a demanda emergente. Atenta a esse movimento, a Associação Brasileira de Supermercados lançou uma cartilha 16 divulgando estratégias para minimizar o risco de contágio, na qual destaca a necessidade de higienização de botões para a emissão do tíquete de estacionamento; carrinhos e cestas de compra; pontos de grande contato como maçanetas, 
corrimãos; terminais de pagamento; caixas eletrônicos e elevadores. Ainda, reforça que devem ficar disponíveis ao público suportes com álcool em gel na entrada da loja e de sabonete e papel toalha nos banheiros. Grandes marcas do segmento supermercadista também se valem de orientações quanto ao acesso às lojas, limitando o número de clientes no interior do estabelecimento e separando horários para os idosos.

A despeito da (des)organização das informações, as mesmas não chegam aos funcionários dos supermercados e aos consumidores como deveriam. Imagens veiculadas nas mídias sociais mostram situações de caos nesses espaços: trabalhadores sem equipamento de proteção individual, seja por dificuldade dos empresários sistematizarem a rotina imposta pela pandemia, ou por completo desconhecimento dos cuidados necessários; aglomeração de pessoas e aquisição de produtos em excesso. Essas situações podem colapsar toda a estrutura de contenção do vírus, promovendo o desabastecimento precoce do segmento.

Outra questão, ligada ao acesso e preparo de refeições, é a possibilidade de contaminação mediante o contato com superfícies inanimadas. Pesquisas revelam que plástico, metal, vidro e papel podem ser veículos de contaminação por coronavírus 17,18. Dessa forma, embalagens de alimentos devem ser higienizadas com água e sabão, ou aplicar álcool $70 \%$ ou solução de hipoclorito de sódio $0,1 \% 18$, conforme disponibilidade no domicílio. Em relação aos alimentos, o uso das boas práticas de higiene já consagradas é necessário, isto porque considerando-se a distribuição dos surtos de doenças de origem alimentar, observa-se que o maior percentual acontece nas residências ${ }^{19}$. Os alimentos devem passar pelo processo de cocção adequada (atingindo $70^{\circ} \mathrm{C}$ em todas as suas partes), e aqueles consumidos crus devem ser previamente lavados e sanitizados ${ }^{8}$ com solução de hipoclorito de sódio $0,1 \% 18$ e, posteriormente, enxaguados com água potável. Ressalta-se que a manipulação de objetos, como o celular, no momento da refeição, pode trazer riscos de contaminação durante a ingestão dos alimentos 20 . Um aspecto importante ainda não mencionado nas orientações até então publicadas, diz respeito à reutilização de sacolas de supermercados para transportar alimentos prontos para o consumo. Essa prática deve ser evitada, uma vez que são veículos de contaminação 21 .

Dada a carência de informações sobre os cuidados durante a higienização, profissionais de algumas universidades públicas estão gerando informes que são divulgados em mídias sociais para o esclarecimento da população. Um dos materiais se refere a orientações sobre o uso de substâncias sanitizantes para a prevenção da COVID-19, com base em um recente trabalho sobre coronavírus 22 . Um outro material publicado trata de uma cartilha sobre os cuidados nutricionais para o enfrentamento do SARS-CoV-2 23. Embasada no Guia Alimentar para a População Brasileira, seus leitores encontram, em uma linguagem simples, orientações que vão desde cuidados de higiene pessoal, dos alimentos e do ambiente de preparo das refeições à preferência por alimentos in natura aos processados e ultraprocessados. O documento também destaca a importância da avaliação crítica das informações, mitos e publicidade veiculados pelas mídias sociais, que por vezes trazem soluções "milagrosas", sem respaldo científico.

A Associação da Indústria de Alimentos dos Estados Unidos 24 publicou dois documentos que trazem recomendações aos proprietários de empresas, servindo de suporte para a orientação de seus funcionários sobre higiene ambiental e pessoal. Destaque é dado à necessidade de capacitação dos colaboradores sobre limpeza e desinfecção adequada das superfícies, uso de equipamentos de proteção individual e dos produtos de higienização, bem como os riscos envolvidos na utilização destes. Ainda, ressalta a necessidade de treinamento quanto aos sintomas da COVID-19 e orientação em caso de contaminação.

A atenção dada pela indústria à doença acontece porque, em situações de crise, a demanda por produtos estocáveis tende a aumentar, o que exige grande planejamento logístico. A população, como forma de se proteger de uma possível escassez, passa a adquirir mais alimentos processados e ultraprocessados, uma vez que estes têm menor perecibilidade, são práticos, de fácil acesso e, por vezes, com menor preço quando comparados aos alimentos frescos. Todavia, o acesso à alimentação equilibrada é imprescindível para o enfrentamento da doença. A segurança alimentar deve ser considerada para além do aspecto higiênico-sanitário.

A tendência de recessão econômica global atinge a todos, mas agrava ainda mais a saúde de grupos populacionais em vulnerabilidade socioeconômica, principalmente aqueles que residem em áreas de 
risco e que compõem a massa de desempregados ou de subempregados no Brasil. Dois grandes eixos precisam ser considerados para essa população:

(i) Viver em áreas de risco como aglomerados subnormais, regiões com baixa cobertura de água e esgoto, dentre outros fatores, dificulta a adoção das medidas de higiene individual e coletiva instituídas para o controle da COVID-19. Uma pesquisa realizada pelo Instituto Brasileiro de Geografia e Estatística revela que apenas 38,2\% dos municípios contavam, em 2017, com uma Política Municipal de Saneamento Básico. A comparação das regiões brasileiras revela disparidades: somente 18,6\% dos municípios do Nordeste relataram ter uma política de saneamento, em detrimento de 63,7\% dos municípios do Sul 25. Como resultado, no Brasil, a média de atendimento total com rede de abastecimento de água foi de $83,6 \%$, em 2018, já o atendimento total com rede de esgotos foi de 53,2\% 26; (ii) As medidas de isolamento domiciliar já estão repercutindo na renda de trabalhadores informais e, em curtíssimo prazo, impactará os assalariados pelo risco de demissão e/ou redução da jornada de trabalho, com consequente diminuição dos seus rendimentos. A fragilização dos vínculos empregatícios já estava em percurso por causa do contexto da crise econômica atual, mas está sendo exacerbada pela pandemia. Nesse sentido, o número de pessoas invisíveis às políticas sociais, especialmente a população em situação de rua, tende a aumentar, no entanto, as ações que já não concretizam o direito à saúde 27 precisarão ser repensadas como forma de proteção a toda sociedade contra o novo coronavírus.

A desarticulação e o enfraquecimento de instâncias importantes para o diálogo sobre segurança alimentar e nutricional, como o Conselho Nacional de Segurança Alimentar, recentemente extinto, demonstra o quão desafiador é o caminho que estamos a percorrer. A condição de insegurança alimentar já instalada será possivelmente acelerada pelo SARS-CoV-2. Nesse sentido, é necessário reavaliar as medidas que concedem mais de $70 \%$ do crédito para o financiamento da produção rural à agricultura patronal, direcionada à produção de commodities, e voltar o olhar para a agricultura familiar, que é mais bem distribuída geograficamente (possibilita o abastecimento local), produz alimentos diversificados, ocupa mais de $80 \%$ dos trabalhadores rurais e faz uso de práticas produtivas mais sustentáveis 28 . Redes alimentares alternativas 29 podem otimizar o acesso a alimentos frescos e saudáveis em tempos de pandemia. Nos documentos consultados não foi mencionada a possibilidade de ajustes de ambientes abertos quanto à comercialização de alimentos, o que sobrecarrega os supermercados e fragiliza ainda mais o sistema agroalimentar.

Até o momento, o que se percebe é uma desarticulação entre as esferas de poder em relação à tomada de decisões. Fundações, conselhos, universidades públicas e associações têm produzido materiais educativos, sendo desconhecido o alcance dos mesmos. O cenário é complexo, dinâmico e exigirá do poder público, da iniciativa privada e da população ações alinhadas para o enfrentamento da COVID-19 sem desconsiderar a insegurança alimentar nas suas várias dimensões. É imprescindível que as medidas de mitigação contra a propagação do SARS-CoV-2 sejam repensadas nos próximos dias. Destacamos que este documento fez um apanhado de informações até o dia 23 de março de 2020. 


\section{Colaboradores}

Todas as autoras contribuíram com a concepção, redação e revisão do artigo.

\section{Informações adicionais}

ORCID: Tatiana Coura Oliveira (0000-0001-63492522); Monise Viana Abranches (0000-0002-80704897); Raquel Martins Lana (0000-0002-75731364).

\section{Agradecimentos}

R. M. Lana é bolsista PDJ Inova Fiocruz.

\section{Referências}

1. World Health Organization. Coronavirus disease (COVID-19) pandemic. https://www. who.int/emergencies/diseases/novel-coronavi rus-2019 (acessado em 19/Mar/2020).

2. Ministério da Saúde. Coronavírus: sobre a doença. http://coronavirus.saude.gov.br/sobrea-doenca\#transmissao (acessado em 19/Mar/ 2020).

3. Assiri A, Al-Tawfiq JA, Al-Rabeeah AA, Al-Rabiah FA, Al-Hajjar S, Al-Barrak A, et al. Epidemiological, demographic, and clinical characteristics of 47 cases of Middle East respiratory syndrome coronavirus disease from Saudi Arabia: a descriptive study. Lancet Infect Dis 2013; 13:752-61.

4. World Health Organization. Coronavirus disease (COVID-19) advice for the public. https:// www.who.int/emergencies/diseases/novelcoronavirus-2019/advice-for-public (acessado em 19/Mar/2020).

5. Agência Nacional de Saúde Suplementar. Coronavírus (COVID-19): confira informações e saiba como se prevenir. http://www.ans.gov. $\mathrm{br} / \mathrm{aans} /$ noticias-ans/consumidor/5344-co ronavirus-confira-informacoes-e-saiba-comose-prevenir (acessado em 19/Mar/2020).

6. Lana RM, Coelho FC, Gomes MFC, Cruz OG, Bastos LS, Villela DAM, et al. Emergência do novo coronavírus (SARS-CoV-2) e o papel de uma vigilância nacional em saúde oportuna e efetiva. Cad Saúde Pública 2020; 36:e00019620.

7. Weston S, Frieman MB. COVID-19: knowns, unknowns, and questions. mSphere 2020; 5:e00203-20.

8. Conselho Federal de Nutricionistas. Recomendações do CFN: boas práticas para atuação do nutricionista e do técnico em nutrição e dietética durante a pandemia de coronavírus. https://www.cfn.org.br/wp-content/ uploads/2020/03/nota_coronavirus_3-1.pdf (acessado em 22/Mar/2020).

9. Secretaria de Estado de Agricultura, Pecuária, Pesca e Abastecimento. Portaria PRESI/CEASA-RJ no 17, de 16 de março de 2020. Estabelece os procedimentos básicos de prevenção de contágio, também em razão do coronavírus (covid19), mediante a continuidade dos serviços essenciais com a instituição do homeoffice. Diário Oficial do Estado do Rio de Janeiro 2020; 18 mar.

10. Distrito Federal. Decreto no 40.520 , de 14 de março de 2020. Dispõe sobre as medidas para enfrentamento da emergência de saúde pública de importância internacional decorrente do novo coronavírus, e dá outras providências. Diário Oficial do Distrito Federal 2020; 14 mar.

11. Rio de Janeiro. Decreto no 46.973, de 16 de março de 2020. Reconhece a situação de emergência na saúde pública do Estado do Rio de Janeiro em razão do contágio e adota medidas de enfrentamento da propagação decorrente do novo coronavírus (COVID-19); e dá outras providências. Diário Oficial do Estado do Rio de Janeiro 2020; 17 mar. 
12. Decretos do Governo de SP com medidas de prevenção e combate ao novo coronavírus. SP Notícias 2020; 26 mar. https://www.saopaulo. sp.gov.br/spnoticias/decretos-do-governode-sp-com-medidas-de-prevencao-e-combate -ao-novo-coronavirus/.

13. Associação Brasileira de Bares e Restaurantes. Bares e restaurantes estimam cortar três milhões de vagas em 40 dias. https://mg.abrasel. com.br/noticias/noticias/bares-e-restaurantes -estimam-cortar-tres-milhoes-de-vagas-em40-dias/ (acessado em 21/Mar/2020).

14. Associação Brasileira de Bares e Restaurantes. Abrasel fecha acordo com iFood: prazo de pagamento para bares e restaurantes será reduzido. https://abrasel.com.br/noticias/noticias/ abrasel-fecha-acordo-com-ifood-prazo-de-pa gamento-para-bares-e-restaurantes-sera-redu zido/ (acessado em 21/Mar/2020).

15. Associação Brasileira de Bares e Restaurantes. Cuidados de higiene no delivery para bares e restaurantes na crise do novo coronavírus. https:// drive.google.com/file/d/1u3vSZDLAqDJe VTLROp5WM5WcTED1tpKV/view (acessado em 21/Mar/2020).

16. Associação Brasileira de Supermercados. Boas práticas para prevenção de Coronavírus (COVID-19) nos supermercados. http://static. abras.com.br/pdf/cartilha_covid.pdf (acessado em 21/Mar/2020)

17. van Doremalen N, Bushmaker T, Morris D, Holbrook M, Gamble A, Williamson B, et al. Aerosol and surface stability of HCoV-19 (SARS-CoV-2) compared to SARS-CoV-1. medRxiv 2020; 9 mar. https://www.medrxiv. org/content/10.1101/2020.03.09.20033217v2.

18. Kampf G, Todt D, Pfaender S, Steinmann E. Persistence of coronaviruses on inanimate surfaces and their inactivation with biocidal agents. J Hosp Infect 2020; 104:246-51.

19. Ministério da Saúde. Surtos de doenças transmitidas por alimentos no Brasil. https://porta larquivos2.saude.gov.br/images/pdf/2018/ja neiro/17/Apresentacao-Surtos-DTA-2018.pdf (acessado em 19/Mar/2020).

20. Cunha CBC, Moraes FR, Monteiro VS, Feitosa FGMA, Silva ITC. Microbiological evaluation of the cell phones of the professionals of a Surgical Center in a beneficent Hospital. J Epidemiol Infect Control 2016; 6:120-4.
21. Repp KK, Keene WE. A point-source norovirus outbreak caused by exposure to fomites. J Infect Dis 2012; 205:1639-41.

22. Escola de Nutrição, Universidade Federal de Ouro Preto. Como limpar mãos, ambientes e utensílios para prevenção do coronavírus (COVID-19). https://enut.ufop.br/news/carti lha-de-orientação-sobre-o-coronavírus (acessado em 27/Mar/2020).

23. Morais AHA, Maia JKS, Damasceno KSFSC, Seabra LMJ, Passos TS. Orientações Nutricionais para o enfrentamento do COVID-19. Universidade Federal do Rio Grande do Norte. https://www.asbran.org.br/storage/arquivos/ CARTILHA_COVID_19\%20final.pdf (acessado em 27/Mar/2020).

24. The Food Industry Association. Coronavirus resources. https://www.fmi.org/food-safety/ coronavirus (acessado em 21/Mar/2020).

25. Instituto Brasileiro de Geografia e Estatística. Perfil dos municípios brasileiros. Saneamento básico: aspectos gerais da gestão da política de saneamento básico: 2017. Rio de Janeiro: Instituto Brasileiro de Geografia e Estatística; 2018.

26. Secretaria Nacional de Saneamento, Ministério do Desenvolvimento Regional. Sistema Nacional de Informações sobre Saneamento: 24o Diagnóstico dos Serviços de Água e Esgotos. http://www.snis.gov.br/downloads/diagnosti cos/ae/2018/Diagnostico_AE2018.pdf (acessado em 23/Mar/2020).

27. Paiva IKS, Lira CDG, Justino JMR, Miranda MGO, Saraiva AKM. Direito à saúde da população em situação de rua: reflexões sobre a problemática. Ciênc Saúde Colet 2016; 21:2595606.

28. Olalde AR. Agricultura familiar e desenvolvimento sustentável. http://www.ceplac.gov br/radar/Artigos/artigo3.htm (acessado 21/ Mar/2020)

29. Darolt MR, Lamine C, Brandenburg A, Alencar MCF, Abreu LS. Redes alimentares alternativas e novas relações produção-consumo na França e no Brasil. Ambiente \& Sociedade 2016; 19:1-22.
Recebido em 22/Mar/2020

Versão final reapresentada em 23/Mar/2020

Aprovado em 25/Mar/2020 